\begin{tabular}{|c|c|c|}
\hline $\begin{array}{l}\text { PKS } \\
\text { PUBLIC } \\
\text { KNDOLEDGE } \\
\text { PROJECT }\end{array}$ & $\begin{array}{c}\text { REVISTA DE GEOGRAFIA } \\
\text { (RECIFE) } \\
\text { http://www.revista.ufpe.br/revistageografia }\end{array}$ & $\begin{array}{l}\text { OJS } \\
\text { OPEN } \\
\text { JOLYNAL } \\
\text { SYSTEMS }\end{array}$ \\
\hline
\end{tabular}

\title{
ANÁLISE DE FRAGILIDADE AMBIENTAL NA BACIA DA BARRAGEM CAMARÁ, AREIA (PB)
}

\author{
Jeferson Mauricio Rodrigues ${ }^{1}$, Gabriel da Nóbrega Monteiro ${ }^{2}$; Jonas Otaviano \\ Praça de Souza ${ }^{3}$
}

${ }^{1}$ Universidade Federal da Paraíba. E-mail: jefersonmrgeo@gmail.com
${ }^{2}$ Universidade Federal da Paraíba. E-mail: gabrielnobregamonteiro@hotmail.com
${ }^{3}$ Universidade Federal da Paraíba. E-mail: jonasgeoufpe@yahoo.com.br

Artigo recebido em 08/12/2017 e aceito em 09/03/2018

\begin{abstract}
RESUMO
O presente trabalho foi feito na bacia hidrográfica da Barragem Camará localizada no Município de Areia (PB). Esta barragem teve um rompimento no ano de 2004, o que trouxe a perspectiva de analisar a situação dessa bacia atualmente, pois, sabendo que uma bacia hidrográfica além de fazer captação da água de chuva, é também o palco que ocorre a produção de sedimento, justifica os estudos voltados a identificação de áreas propensas à erosão. Dessa forma, entender as áreas com maiores indícios de fragilidade, traz à luz a perspectiva de desenvolver gestões para recuperação ou preservação de áreas susceptíveis à erosão. A metodologia consiste numa adaptação de ROSS (1994), CREPANI (1996) e ROMANO (2016), no intuito de atingir aos objetivos levantados por este trabalho. Concluindo que a barragem possui 4 pontos mais susceptíveis à erosão, cada um com uma característica similar, desenvolvida pela interação dos elementos do sistema ambiental associados ao fator antrópico.
\end{abstract}

Palavras-chave: Fragilidade; Bacia de drenagem; Barragem.

\section{ANALYSIS OF ENVIRONMENTAL FRAGILITY IN THE BASIN OF CAMARÁ DAM, AREIA (PB)}

\begin{abstract}
The present work was done in the catchment area of the Camará Dam located in the Municipality of Areia (PB). This dam had a rupture in the year 2004, which brought the perspective of analyzing the situation of this basin today, since, knowing that a watershed besides making rainwater capture, it is also the stage that occurs the production of sediment, justifies studies aimed at identifying areas prone to erosion. In this way, understanding the areas with the greatest signs of fragility brings to light the prospect of developing managements for the recovery or preservation of areas susceptible to erosion. The methodology consists of an adaptation of ROSS (1994), CREPANI (1996) and ROMANO (2016), in order to reach the objectives raised by this work. In conclusion, the dam has 4 points more susceptible to erosion, each with a similar characteristic, developed by the interaction of the elements of the environmental system associated with the anthropic factor.
\end{abstract}

Key-words: Fragility; Drainage Basin; Dam.

\section{INTRODUÇÃO}

Tendo como base que o modelado terrestre é um resultado dos esforços endógenos associados aos exógenos, ele se apresenta de diferentes formas na superfície da terra. Assim, numa perspectiva holística, é possível avaliar e identificar parte dos elementos em constante 
interação que atuam a partir da entrada e saída de energia no sistema ambiental físico. Ou seja, toda essa dinâmica pode gerar um grau de estabilidade ou instabilidade geomórfica para determinadas áreas, fazendo com que sejam necessários modelos de análise, que correspondam ao objetivo da pesquisa.

Deve-se levar em consideração, também, que o papel do homem na alteração das formas da paisagem, é hoje, mais do que nunca, extremamente relevante para as análises do sistema ambiental físico, sendo impossível uma maior aproximação da realidade considerando apenas os fatores naturais do sistema. Com isto em mente, Santos (2015) afirma que as ocupações irregulares em áreas propensas a riscos estão ocorrendo de forma mais intensificada, desenvolvendo preocupação para a identificação de áreas mais vulneráveis a riscos. Ross (1994), as interferências antrópicas trouxeram alterações na dinâmica natural do sistema ambiental físico, sendo necessários estudos analíticos de fragilidade, que são de suma importância para a gestão ambiental, onde a sustentatibilidade, conservação e recuperação são elementos basilares para seu estudo.

Com isso, Santos (2010) afirma que é importante a identificação dos elementos do sistema ambiental para que se possa compreender os níveis de fragilidade gerados a partir da interação dos elementos ambientais, tais como: geologia, geomorfologia, solo, clima, vegetação, uso e cobertura e declividade são indicadores de fragilidade numa perspectiva unificada. Dessa forma, Romano (2016) embasada em Tricart (1977) afirma que existem três perspectivas de análise de sistema ambiental, que são meios estáveis, intergrades e instáveis, onde o primeiro corresponde a uma área mais resistente aos fatores desagreg200ação, os intergrades são áreas de transição de um ambiente estável para um instável, e o último são áreas propensas à erosão.

Mas para identificar esses diferentes níveis da fragilidade é importante conhecer os elementos do sistema ambiental e suas inter-relações. Para Tricart apud, Ross (1994) o ambiente só está estabilizado quando se conserva em equilíbrio, que, de modo contrário, o desequilíbrio é indicador da instabilidade. Em tais citações, Tricart e Ross consideraram o relevo como principal indicador da estabilidade da área, ou seja, seu índice de dissecação. Contudo, Ross desenvolveu um trabalho onde as classes de declividade eram o elemento de maior importância para identificação dos ambientes de fragilidade.

Assim, o objetivo é calcular a fragilidade ambiental na bacia da Barragem Camará, no Município de Areia, Brejo paraibano (PB). A Bacia da Barragem Camará rompeu no ano de 2004, no Município de Areia na Paraíba, Região Nordeste do Brasil (Fig. 1). Sua área 
apresenta uma parte com um clima tropical úmido, e outra de clima tropical seco. O relevo da bacia hidrográfica apresenta-se principalmente de suave ondulado a ondulado, com uma amplitude altimétrica de $400 \mathrm{~m}$. A geologia é predominantemente cristalina, com solos pouco desenvolvidos em sua superfície e vegetação predominantemente de caatinga arbustiva arbórea fechada, mas com a maior extensão ocupada pelo antropismo. Levando em conta que houve o rompimento dessa barragem no ano de 2004, o estudo é de vital importância para identificar os diferentes níveis de fragilidade que a área apresenta atualmente, considerando que a bacia de drenagem além de fazer a captação de chuva, também é palco de produção de sedimento, que no rompimento teve remobilização dos recursos hidrossedimentológicos. $\mathrm{Ou}$ seja, o trabalho serve como base para eventuais estudos voltados ao planeamento e gestão dessas áreas mais propensas à erosão.

\section{MATERIAL E MÉTODOS}

\section{Área de estudo}

O trabalho foi realizado na Bacia da Barragem Camará, que rompeu no ano de 2004, no Município de Areia na Paraíba, Região Nordeste do Brasil (Fig. 1). Este Município está inserido na região do Brejo paraibano, onde sua área apresenta uma parte com um clima tropical úmido, e outra de clima tropical seco.

O relevo da bacia hidrográfica apresenta-se principalmente de suave ondulado a ondulado, com uma amplitude altimétrica de $400 \mathrm{~m}$. A geologia é predominantemente cristalina, com solos pouco desenvolvidos em sua superfície e vegetação predominantemente de caatinga arbustiva arbórea fechada, mas com a maior extensão ocupada pelo antropismo. 
Figura 1 - Mapa de localização utilizando o Modelo Digital de Elevação para representar a Hipsometria da área

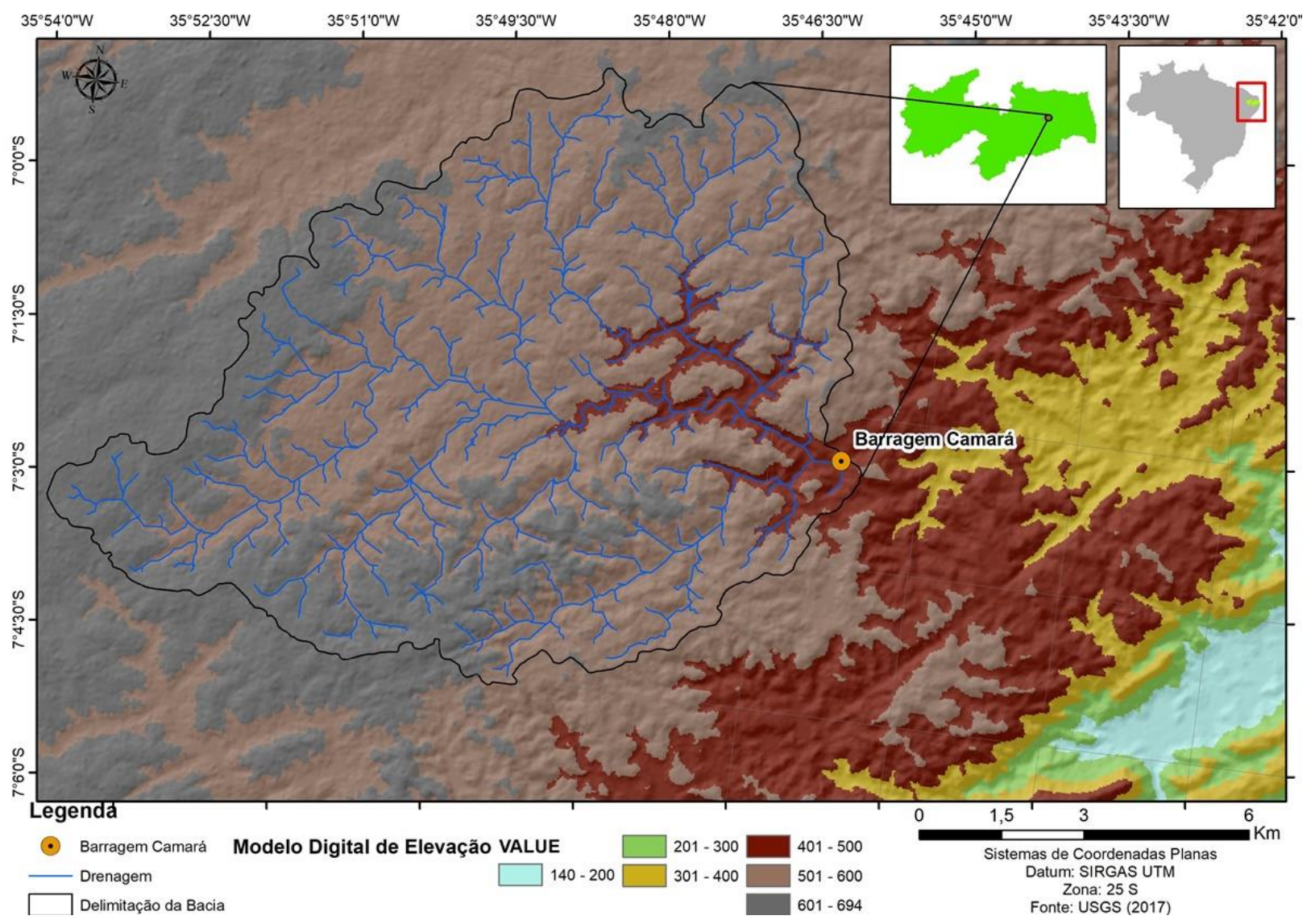

Fonte: Elaborado pelos autores (2017).

\section{Metodologia}

Dado o exposto, o presente trabalho é uma adaptação das metodologias de ROSS (1994), CREPANI (1996) e ROMANO (2016), onde o primeiro atribui o nível de fragilidade principalmente à declividade, o segundo as outras variáveis complementares, e o terceiro ao fato de ter sido um estudo elaborado para ambiente seco. $\mathrm{O}$ modelo de fragilidade com apoio nas classes de declividade é baseado na perspectiva de 4 elementos indicadores na paisagem, que são: declividade, solo, uso e cobertura, e clima. Já o método criado por Crepani (1996) apud. Spörl (2004) é baseado nos índices de dissecação do relevo considerando 5 elementos.

Assim, cada variável da paisagem recebe um valor final resultante da média aritmética dos valores individuais, segundo uma equação que busca representar a escala de vulnerabilidade natural à perda de solo, na seguinte equação: 
Onde: $G=$ geologia, $R$ Geomorfologia, $S=$ Solos, $V=$ Vegetação $=, C=$ Clima .

Contudo, os métodos apresentados não atendem à necessidade dos objetivos deste trabalho, o que levou a uma adaptação de tais metodologias, onde são tidas como complementares, podendo evidenciar uma maior aproximação da realidade do sistema ambiental. Dessa forma, a metodologia que aqui é utilizada, é uma junção das duas citadas acima, onde cada elemento assume uma divisão por classes de fragilidade individual, ou seja, a declividade possui uma divisão de 5 categorias de fragilidade, como também, os demais elementos da paisagem, o que trás a essa perspectiva a possibilidade de entender o grau de fragilidade a partir de cada elemento, para posteriormente, juntar todas as informações no intuito de inferir sistematicamente o resultado pelo cálculo aritmético ponderado a partir da soma dos dados de cada elemento.

Esses valores de fragilidade serão obtidos a partir de uma adaptação da metodologia de Ross (1994), e sendo necessária também uma adaptação na abordagem à geologia, onde Romano (2016) dividiu as classes de acordo com suas características mineralógicas na escala de dureza de Mohs. Assim, levando ao modelo de análise de fragilidade da geologia. Dado o exposto, foram elaborados 5 mapas integrados de fragilidade, um para cada variável de análise, a partir de dados secundários obtidos pelo IDEME (2011).

Sendo assim, os shapefiles serão trabalhados em ambiente GIS, onde a ferramenta clip do Analise Tools, permite uma extração das informações de cada shapefile para o recorte da área, para posteriormente, elaborar os mapas temáticos. A partir da soma de todas essas terminações por algoritmos referentes as classes de fragilidade de cada elemento do sistema ambiental, será possível calcular o grau de fragilidade, a partir da transformação dessas informações em raster pela ferramenta conversion tools - polígono to raster, e posteriormente, fazer o cálculo pela ferramenta Map algebra - raster calculator consistindo na seguinte fórmula:

$$
(\text { Solo }+ \text { Uso e Cobertura }+ \text { Clima }+ \text { Geologia }+(\text { Declividade } * 6)) / 10
$$

A fórmula propõe uma análise aritmética ponderada dos valores das variáveis já citadas, onde, a declividade assume peso maior em relação às outras, já que segundo ROSS (1994), ela possui uma influência maior sobre as demais consideradas. 


\section{RESULTADOS E DISCUSSÕES}

Nessa perspectiva, a partir da elaboração de uma tabela com as informações de fragilidade para cada um dos elementos analisados no sistema, pode-se ter uma ideia das áreas propensas aos fatores erosivos (Quadro. 1). Assim, a declividade apresenta 5 classes específicas referentes à inclinação de sua superfície no modelado, ou seja, a declividade é dividida em 5 categorias, de acordo com a classificação da EMBRAPA (2006): Plano - <3\% (Classe 1); Suave Ondulado - 3 a $8 \%$ (Classe 1); Ondulado - 8 a $20 \%$ (Classe 2); Forte Ondulado - 20 a $45 \%$ (Classe 3); Montanhoso - 45 a $150 \%$ (Classe 4); Escarpado - > $150 \%$ (Classe 5).

Quadro 1 - Tabela de Classes de Fragilidade Individual para cada Elemento do Sistema Ambiental

\begin{tabular}{|c|c|c|c|}
\hline ELEMENTOS & CARATERÍSTICAS & CLASSES & $\begin{array}{c}\text { PESO NA } \\
\text { FÓRMULA }\end{array}$ \\
\hline \multirow{5}{*}{ DECLIVIDADE } & Plano e Suave Ondulado & 1 & \multirow{5}{*}{$60 \%$} \\
\hline & Ondulado & 2 & \\
\hline & Forte Ondulado & 3 & \\
\hline & Montanhoso & 4 & \\
\hline & Escarpado & 5 & \\
\hline \multirow[b]{5}{*}{ SOLO } & Latossolo & 1 & \multirow{5}{*}{$10 \%$} \\
\hline & Argissolo & 2 & \\
\hline & Luvissolo Crômico e Vertissolo & 3 & \\
\hline & Neossolo Regolítico & 4 & \\
\hline & $\begin{array}{c}\text { Neossolo Litólico e Afloramento de } \\
\text { Rocha }\end{array}$ & 5 & \\
\hline \multirow[b]{2}{*}{ CLIMA } & Tropical Umido & 3 & \multirow{2}{*}{$10 \%$} \\
\hline & Tropical Seco & 5 & \\
\hline \multirow{4}{*}{ GEOLOGIA } & $\begin{array}{l}\text { Migmatito, Metagranito, Metamonzogranito, } \\
\text { Metassienito, Metassienogranito }\end{array}$ & 2 & \multirow{4}{*}{$10 \%$} \\
\hline & $\begin{array}{l}\text { Diorito, Granito, Granodiorito, Quartzo } \\
\text { monzonito, Monzogranito }\end{array}$ & 3 & \\
\hline & $\begin{array}{l}\text { Metadacito, Metarriodacito, Metagrauvaca, } \\
\text { Metachert, Paragnaisse, Metabassalto, } \\
\text { Metagabro, Metavulcanoclática, Migmatito, } \\
\text { Biotita-muscovita-quartzo xisto }\end{array}$ & 4 & \\
\hline & Areniticas e argilosas & 5 & \\
\hline \multirow{5}{*}{$\begin{array}{c}\text { USO E } \\
\text { COBERTURA }\end{array}$} & Mata Úmida & 1 & \multirow{5}{*}{$10 \%$} \\
\hline & Mata Semidecidual & 2 & \\
\hline & Caatinga Arbórea Fechada & 3 & \\
\hline & Caatinga Arbustiva Fechada & 4 & \\
\hline & Caatinga Arbustiva Aberta e Antropismo & 5 & \\
\hline
\end{tabular}

Fonte: Adaptado de ROSS (1994); CREPANI (1996); e ROMANO (2016).

Segundo essa classificação, os relevos acima de $20 \%$ de inclinação apresentam maior propensão à atuação dos fatores erosivos, pela sua maior inclinação. Essas áreas mais íngremes foram identificadas principalmente nas áreas próximas dos ambientes fluviais, como também, em áreas que apresentam rupturas de declive, acentuando a inclinação da superfície e 
gerando processos erosivos. O solo também apresenta 5 classes de fragilidade (Quadro 1), mas no recorte da bacia as fragilidades predominantes são a 2 (argissolos) e 4 (neossolo regolítico), assim, os argissolos nas áreas de menor declividade apresentam maior estabilidade sendo mais coesos e com maior; e o neossolo regolítico são solos relativamente rasos com uma média de $20 \mathrm{~cm}$ de profundidade, refletindo o caráter da rocha matriz.

O clima apresenta duas variações de fragilidade para a área, mas, o que está predominantemente dentro do recorde da bacia é o tropical seco, com uma classificação de fragilidade de classe 5, sendo assim, muito agressivo, pois considerando que as chuvas nas áreas de clima tropical seco ocorrem de forma concentrada e mal distribuída, é capaz de gerar morfogênese em maior intensidade que o clima tropical úmido.

A geologia da área apresenta 4 classes de fragilidade, das quais, as três principais são as classes 2 (metamórficas), 3 (ígneas) e 4 (metamórficas), onde a diferença das classes 2 e 4 é o nível de dureza apresentada pelas rochas constituintes, onde os minerais constituintes são diferentes, ou seja, são rochas cristalinas que diferem a partir da escala de dureza de suas estruturas mineralógicas, sendo assim, onde as metamórficas da classe 4 têm menor escala de dureza em relação às da classe 2 .

Posteriormente, foram elaborados mapas por índice de fragilidade a partir das informações de classes de cada elemento, fornecendo um entendimento da área a partir dos elementos individuais do sistema ambiental físico (Fig. 2), possibilitando posteriormente o cálculo de fragilidade pela média aritmética ponderada.

Nessa perspectiva, como o trabalho é numa perspectiva sistêmica, todos esses dados precisam ser analisados de forma interligada/conjunta, que a partir da metodologia proposta, foi possível somar todos os valores referentes a cada classe de fragilidade dos elementos e gerar um dado pela média aritmética ponderada, ou seja, um dos elementos apresenta peso maior na equação (declividade), onde a fragilidade apresenta peso de $60 \%$ no cálculo e os demais elementos apresentam $10 \%$.

Após a definição do cálculo ponderado de fragilidade, foi possível a elaboração de um mapa de fragilidade, o qual identifica as áreas de maior e menor estabilidade. Posteriormente, foram selecionados pontos de fragilidade mais intensa para analisar a importância de cada elemento do sistema ambiental, suas inter- relações e dinamicidade (Fig. 3). Nessa perspectiva, o ponto 1 está localizado a noroeste da bacia hidrográfica da Barragem Camará, mais precisamente próximo a sua cabeceira, tendo uma amplitude altimétrica de $200 \mathrm{~m}$, ou 
seja, sua área de cimeira apresenta valores próximos de $700 \mathrm{~m}$ e as depressionárias com 500 $\mathrm{m}$ em uma distância relativamente pequena, fazendo com que haja uma ruptura de declive.

Seu substrato é composto por rochas ígneas, que associado a um clima tropical seco, gerou um neossolo regolítico e alguns afloramentos de rocha, permitindo apenas o desenvolvimento de uma vegetação de caatinga aberta, associados, também, a um forte antropismo.

Figura 2 - Indices De Fragilidade Por Elemento: (a) Declividade; (b) Solos; (c) Uso e ocupação; (d) Clima; (e) Geologia

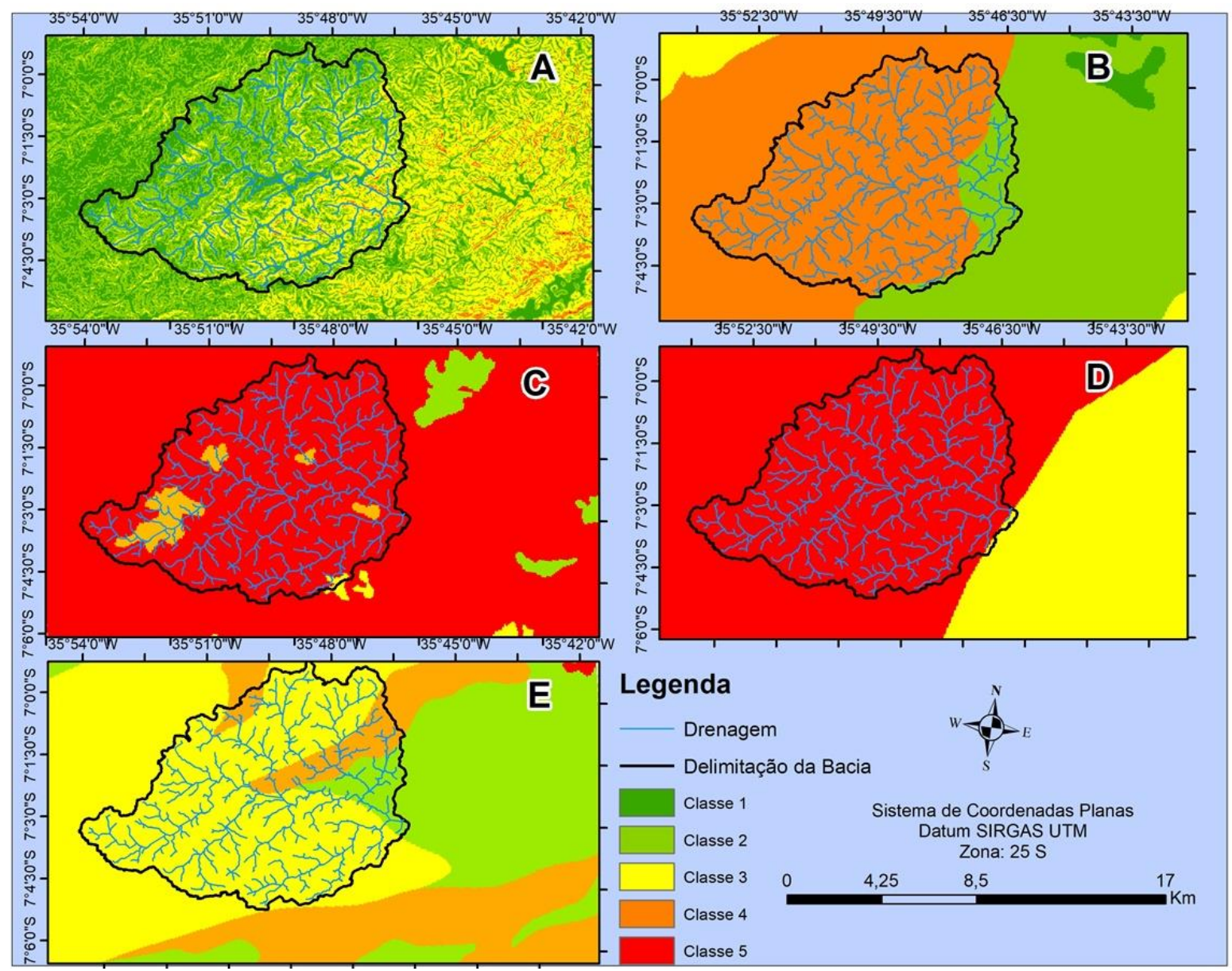

Fonte: Elaborado pelos autores (2017).

Assim, todas essas características interligadas provocaram uma área com fragilidade de classes 2,3 e 4, onde as áreas de menor nível de fragilidade nesse ponto estão associadas a suavidades no caráter horizontal do modelado, ou seja, menores declividades (Fig. 3). O ponto 2 está localizado a nordeste, e sua amplitude altimética está em torno de $200 \mathrm{~m}$, onde as áreas mais elevadas alcançam valores próximos a $600 \mathrm{~m}$ e as mais baixas em $400 \mathrm{~m}$. 
A geologia é composta por rochas metamórficas, como no ponto 1, mas suas composição mineral dá maior nível de estabilidade, em comparação ao nível de fragilidade do ponto 1, que associado a um clima tropical seco, desenvolve um neossolo regolítico com afloramento de rocha, ou seja, na mesma proporção que no ponto 1 . A vegetação também não varia, como também, o uso antrópico intensivo é presente, mas a declividade na área é predominantemente mais acentuada, não permitindo áreas de superfície suave (Fig. 3).

Figura 3 - Mapa Geral de Declividades por Média Aritmética Ponderada, indicando os locais mais Propícios à Erosão

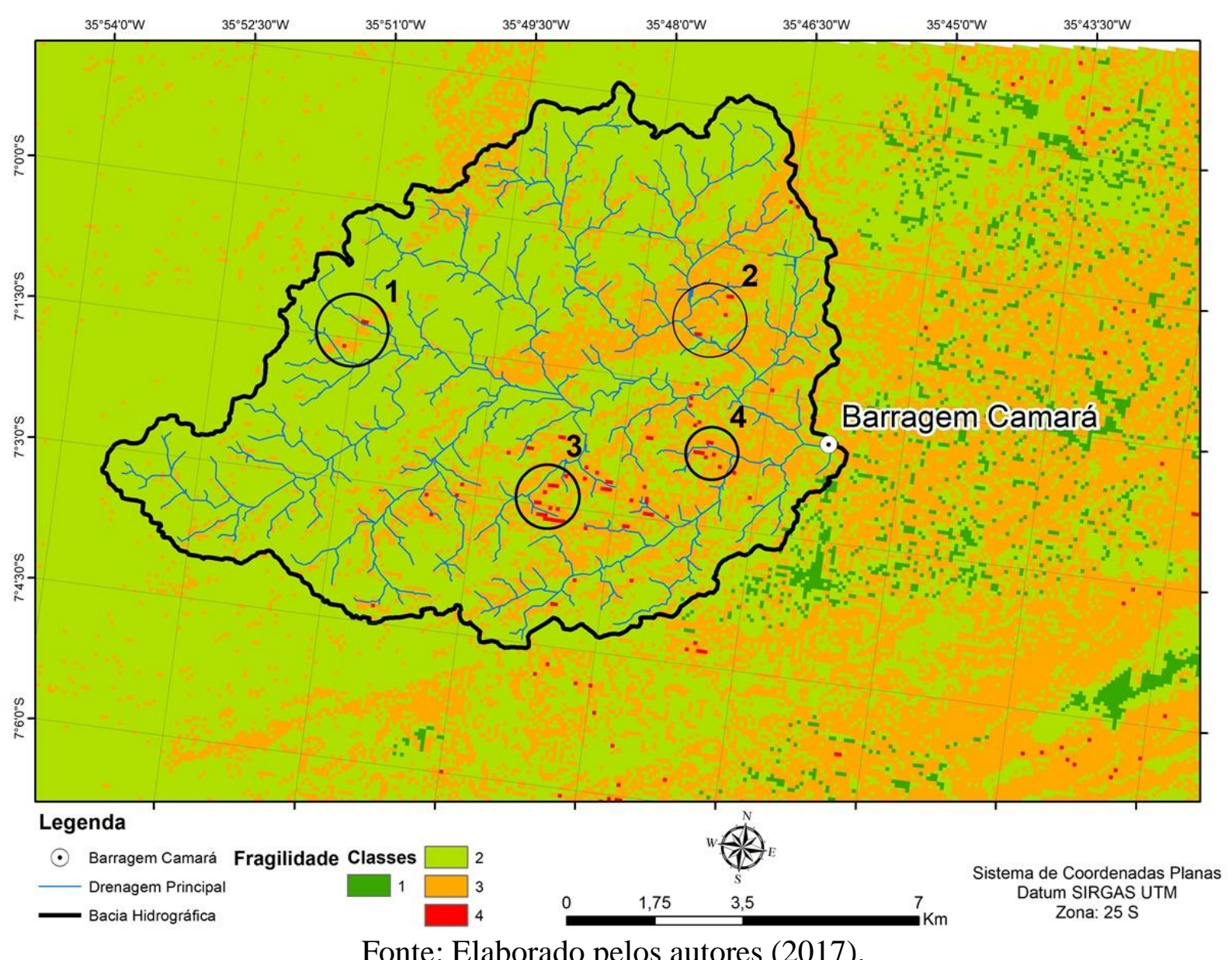

O ponto 3 está localizado ao sul da bacia, com uma amplitude altimétrica também de $200 \mathrm{~m}$, onde as áreas mias altas alcançam valores próximos a 700 m, e as mais baixas em torno de $500 \mathrm{~m}$, também em uma pequena distância. A geologia é composta por rochas do tipo ígneas, que associado a um clima tropical seco, gera um neossolo regolítico (que já foi caracterizado anteriormente), e a vegetação e uso também são semelhantes ao ponto anterior, apresentando pouca modificação ao ponto anterior (Fig. 3). 
O ponto 4 está localizado a sudeste, sendo o que apresenta a menor amplitude altimétrica, com $100 \mathrm{~m}$ de amplitude também numa pequena distância, onde o valor da área mais alta está em torno de $500 \mathrm{~m}$, e a mais baixa em $400 \mathrm{~m}$. Contudo, a geologia continua sendo caracterizada por rochas ígneas, que associadas a um clima tropical seco, desenvolvem dois tipos de solo: neossolo regolítico, com características já citadas anteriormente; e um solo argiloso quanto mais próximo da foz, onde esse solo tem maior espessura e maior capacidade de infiltração, que associada a uma coesão entre seus grãos, apresenta maior frente aos fatores intempéricos, e consequentemente, maior resistência.

$\mathrm{O}$ antropismo ainda é fator intenso na área, mas ocorre a presença de uma vegetação do tipo caatinga arbórea fechada. O relevo por sua vez, é caracterizado de ondulado a escarpado, não apresentando áreas planas ou semiplanas (Fig. 3). Dado o exposto, a fragilidade ocorre nos ambientes que apresentam maior inclinação do relevo, que associados a rochas expostas e um clima tropical úmido, desenvolve na maioria das vezes um solo raso e pouco drenado. Nessa perspectiva, a partir dos eventos de chuva, que como foi dito anteriormente, ocorrem de forma intensa e mal distribuída, faz com que a capacidade de infiltração nessas áreas seja superada pelo volume de precipitação facilmente, produzindo escoamento superficial não canalizado e erosão desse material, que é transportado para as áreas mais baixas e depositados nas zonas de baixa energia.

Com isso, a partir do momento em que esse transporte começa a alcançar as áreas mais baixas e menos íngremes (baixa energia), pode gerar solos mais desenvolvidos, como é o caso do ponto 4, e numa retroalimentação que é uma circularidade de ação, propiciar ambientes de desenvolvimento de uma vegetação mais densa e distribuída, aumentando a resistência da área e consequentemente, diminuindo seu grau de fragilidade.

\section{CONSIDERAÇÕES FINAIS}

Os resultados obtidos trouxeram à luz que o método adaptado correspondeu aos objetivos levantados na introdução. Ou seja, o fato das metodologias de fragilidade serem elaboradas principalmente para ambientes úmidos, requer que tais modelos tenham adaptações, no intuito de refletir sobre o funcionamento e identificação dos elementos do sistema ambiental semiárido, que apresenta singularidades e um déficit de estudos para uma área tão significativa para a região Nordeste do Brasil, como também, para o país, pela grande quantidade demográfica que ocupa tal região. Assim, os estudos voltados aos recursos hidrossedimentológicos, e suas respectivas bacias hidrográficas no semiárido, são 
imprescindíveis para elaborar gestões e políticas públicas no intuito de preservar os ambientes estáveis, e recuperar áreas degradadas. Nessa perspectiva, importância do trabalho é relevante pelo fato de essa como qualquer outra bacia hidrográfica apresentar seus diferentes níveis de fragilidade, sendo assim, tendo como base que todo e qualquer reservatório possui um tempo de vida útil, é necessário trabalhos desenvolvidos no intuito de identificar e compreender as áreas mais susceptíveis à erosão, para gerar gestões adequadas para essas áreas que apresentam níveis avançados de fragilidade.

\section{REFERÊNCIAS}

ROMANO, M. Análise da fragilidade ambiental, na bacia do Riacho Jucurutu/Raposa em São João do Tigre. 2016. 70 f. Monografia, Universidade Federal da Paraíba. p. 45 - 47. 2016.

ROSS, J. Análise empírica da fragilidade dos ambientes naturais e antropizados. V. 8. Revista do Departamento de Geografia. Departamento de Geografia - FFLCH. 1994. SANTOS, R. Análise de fragilidade ambiental no Município de Tamboara - PR: Aplicação e estudo comparativo de duas metodologias. Geoambiente online. UFG. Goiás. 2010.

SPÖRL, C. Análise comparativa da fragilidade ambiental com aplicação de três modelos. GEOUSP, Espaço e Tempo. São Paulo. 2004. 